\title{
Utilization of antenatal care services in Syrian refugee camps in Erbil, Iraq
}

\begin{abstract}
Background and Objective: Antenatal care can help in preparing women for delivery in addition to raising awareness about the warning signs during pregnancy. This study aimed to assess the pattern of utilization of antenatal care services by the pregnant women in Syrian refugee camps in Erbil.

Methods: A cross-sectional study was conducted at the four Syrian refugee camps in Erbil between $1^{\text {st }}$ June 2015 and $1^{\text {st }}$ March 2016. A sample of 470 newly delivered women was included in the study. Data was collected through a specially designed questionnaire.

Results: The majority of the women $(99.6 \%)$ had at least one antenatal care visit during pregnancy with $73.6 \%$ having adequate antenatal care visits. About $64 \%$ of the women visited both the public and private health sectors. A statistically significant higher proportion of employed women utilized adequate antenatal care services than the non-employed women $(84 \%$ vs. $63.4 \%, P=0.036)$. There was no statistically significant association between the mothers' age and education with the utilization of adequate antenatal care.

Conclusion: A high proportion of women in the Syrian refugee camps in Erbil received antenatal care services during the last pregnancy with a relatively important proportion of them receiving adequate care and having early initiation of antenatal care visits. Further studies are needed to examine the quality of the antenatal care services in the refugee camps and women's satisfaction with these services.
\end{abstract}

Keywords: Antenatal care; Utilization; Syrian refugee camps.

\section{Introduction}

Antenatal care is primarily aimed to achieve a healthy mother and a healthy baby at the end of pregnancy. More specifically, antenatal care aims to detect early factors that may increase the perinatal risk of pregnancies, intervene to improve outcomes, educate all who provide or receive care and help to make pregnancy and birth a positive life experience. Antenatal care should begin soon after conception and needs to be continued throughout pregnancy. ${ }^{1,2}$ Extraordinary attention should be given to antenatal care by the healthcare systems. The objectives of antenatal care are to prevent health problems in both infants and mothers and to ensure a good start for each newborn child. The care for each pregnant woman needs to be individualized, based on her own needs and wishes. ${ }^{1}$ Antenatal care can help in preparing women for delivery in addition to raising awareness about the warning signs during pregnancy. Antenatal care with trained health workers can help in preventing, detecting, and treating many health problems in pregnant women. A minimum of four antenatal visits is recommended during pregnancy. Antenatal care services comprise interventions such as tetanus toxoid vaccination, screening, and treatment for infections, and identification of warning signs during pregnancy. During the period from 2000 to 2008 , less than half of pregnant women in the world received the recommended minimum of four visits, but around $78 \%$

${ }^{1}$ Directorate of Health, Erbil, I raq, Erbil, I raq.

2 Department of Community Medicine, College of Medicine, Hawler Medical University, Erbil, I raq.

* Correspondence: kamaran742003@yahoo.com 
had at least one visit. In low-income countries, only $39 \%$ of pregnant women received four or more antenatal visits during 2000-2008., In developing countries, the proportion of pregnant women who had at least one antenatal visit remarkably increased from around $64 \%$ in the 1990 s to around $80 \%$ in $2008 .{ }^{5}$ However, there has been a slight improvement in the proportion of women receiving at least four antenatal visits over a similar period. The long years of violence in Syria have resulted in the displacement of millions of Syrians. By May 2014, an estimated 9 million Syrians had been displaced, including 2.7 million who have crossed borders to seek refuge in Lebanon, Jordan, Turkey, and Iraq. ${ }^{6}$ Antenatal care delivery to tens of thousands of pregnant Syrian refugee women is critical to prevent maternal and fetal mortality but is not well characterized given the multiple factors obtaining health data in a displaced population. Limited knowledge is available about the status of antenatal care services to the women in Syrian refugee camps in Erbil, Iraq. This study aimed to assess the pattern of utilization of antenatal care services by the pregnant women in Syrian refugee camps in Erbil.

\section{Methods}

A cross-sectional study was conducted at the four Syrian refugee camps in Erbil governorate; Kawargosk, Darashakran, Qushtapa, and Basra. An estimated 34,250 persons live in the four Syrian refugee camps in Erbil; 10,000 persons in Kawargosg camp, 15,000 persons in Dara-shakran camp, 6,000 persons in Qushtapa camp and 3,250 persons in Basrma camp. Data were collected during the period from $1^{\text {st }}$ June 2015 to $1^{\text {st }}$ March 2016. A sample of 470 newly delivered women from the four Syrian refugee camps was included. All the women delivered during the study period were identified and interviewed either during their visits to the vaccination units or by visiting them at their shelters. Data collection was done by direct interview through a specially designed questionnaire by the researchers that included information about the sociodemographic characteristics, the obstetric history of the women and details about the utilization of the antenatal care services. Information about antenatal care services included receiving antenatal care during the last pregnancy, the starting time of receiving antenatal care in the trimesters of gestation, and the source of antenatal care (private or public healthcare sector). The WHO recommendation for adequate antenatal care was used in this study. ${ }^{7}$ This includes having four antenatal care visits for women with normally progressing pregnancies with the first visit in the first trimester (ideally before 12 weeks but no later than 16 weeks), followed by 24-28 weeks, 32 weeks and 36 weeks was considered. $^{7,8}$ The aims, contents, and other aspects of the study were explained for each woman, and verbal informed consent was obtained from all participants. The scientific and the research ethics committees at the authors' institution approved the study protocol. Institutional permission and access to the camps were obtained from the Directorate of Health of Erbil. The statistical package for the social sciences (version 21) was used for data entry and analysis. Both descriptive and analytic approaches were employed. The descriptive approach included calculating frequencies, percentages, and means. In the analytic approach, the Chi-square test was used to assess the association between the categorical variables. A $P$ value of $\leq 0.05$ was considered statistically significant.

\section{Results}

A total number of 470 newly delivered women participated in the study. Their age ranged from 15 to 40 years with a mean \pm SD of $26.34 \pm 5.2$ years, and their age at marriage ranged from 14 to 32 years with a mean $\pm S D 20.43 \pm 3.18$ years. Table 1 shows the distribution of the women in the camps, their age groups with the age 
at marriage, educational level, and their occupation. Most newborn babies were delivered by normal vaginal delivery $(71.5 \%)$, and the remaining $28.5 \%$ were delivered by cesarean section. The highest proportion of mothers had one or two previous pregnancies $(47.9 \%)$ and had a party of $1-3(45.5 \%)$, as shown in Table 2.

Table 1: Socio-demographic characteristics of the study sample.

\begin{tabular}{lcc}
\hline Characteristics & No. & $\mathbf{( \% )}$ \\
\hline Mother's age (Years) & 41 & $(8.7)$ \\
$<20$ & 142 & $(30.2)$ \\
$20-24$ & 156 & $(33.2)$ \\
$25-29$ & 91 & $(19.4)$ \\
$30-34$ & 40 & $(8.5)$ \\
$35+$ & & \\
Mother's age at marriage (Years) & 82 & $(17.4)$ \\
$<18$ & 388 & $(82.6)$ \\
$\geq 18$ & & \\
Mother's educational level & 107 & $(22.8)$ \\
Illiterate or read and write & 212 & $(45.1)$ \\
Primary & 98 & $(20.8)$ \\
Secondary & 53 & $(11.3)$ \\
Higher Education & & \\
Mother's Occupation & 445 & $(94.7)$ \\
Housewife & 25 & $(5.3)$ \\
Semi-Skilled or Non-Manual Skilled & & \\
Camps & 204 & $(43.4)$ \\
Darashakran & 97 & $(20.7)$ \\
Basra & 88 & $(18.7)$ \\
Qushtapa & 81 & $(17.2)$ \\
Kawargosk & 470 & $(100)$ \\
Total & & \\
\hline
\end{tabular}

Table 2: History of delivery in the last pregnancy.

\begin{tabular}{lcc}
\hline Variable & No. & $(\%)$ \\
\hline Mode of delivery & & \\
Normal Vaginal & 336 & $(71.5)$ \\
Cesarean Section & 134 & $(28.5)$ \\
No. of previous pregnancies & & \\
$1-2$ & 225 & $(47.9)$ \\
$3-4$ & 155 & $(33)$ \\
$\geq 5$ & 90 & $(19.1)$ \\
Maternal Parity & & \\
$1-3$ & 256 & $(54.4)$ \\
$4-7$ & 153 & $(32.6)$ \\
$\geq 8$ & 61 & $(13)$ \\
Total & 470 & $(100)$ \\
\hline
\end{tabular}


Pregnant women who visited antenatal care units for at least one time during the last pregnancy constituted $99.6 \%$. Of these, $35.5 \%$ attended antenatal care units for 1-3 times, $59.4 \%$ had $4-7$ visits, and $5.1 \%$ attended antenatal care units for 8 or more times. Most women (63.8\%) received antenatal care services from both the public and the private sectors. Majority of the women had the first visit to the antenatal care unit during the first trimester (93.2\%) and the last visit during the third trimesters (96.6\%). The most common antenatal care service received was ultrasonography examination (99.1\%) followed by blood pressure checking $(94.7 \%)$, general urine analysis $(67.4 \%)$ and blood sugar checking (23\%). Most women received iron and folic acid tablets $(92.8 \%)$ and tetanus vaccine $(66.8 \%)$. These findings are shown in Table 3.

Table 3: Antenatal care during the current pregnancy.

\begin{tabular}{|c|c|c|}
\hline Variable & No. & (\%) \\
\hline \multicolumn{3}{|c|}{ Attendance at antenatal care centers $(n=470)$} \\
\hline Yes & 468 & $(99.6)$ \\
\hline No & 2 & $(0.4)$ \\
\hline \multicolumn{3}{|c|}{ Adequate antenatal care visit $(n=468)$} \\
\hline Yes & 303 & $(64.7)$ \\
\hline No & 165 & $(35.3)$ \\
\hline \multicolumn{3}{|c|}{ No. of antenatal care visits $(n=468)$} \\
\hline $1-3$ & 165 & $(35.3)$ \\
\hline $4-7$ & 279 & $(59.6)$ \\
\hline $8-12$ & 24 & $(5.1)$ \\
\hline \multicolumn{3}{|c|}{ Place of antenatal care $(n=468)$} \\
\hline Private Sector & 22 & $(4.7)$ \\
\hline Public Sector & 146 & $(31.2)$ \\
\hline Both Sectors & 300 & $(64.1)$ \\
\hline \multicolumn{3}{|c|}{ First antenatal care visit $(n=468)$} \\
\hline 1st Trimester & 436 & $(93.2)$ \\
\hline 2nd Trimester & 30 & $(6.4)$ \\
\hline 3rd Trimester & 2 & $(0.4)$ \\
\hline \multicolumn{3}{|c|}{ Last antenatal care visit $(n=468)$} \\
\hline 1st Trimester & 3 & $(0.6)$ \\
\hline 2nd Trimester & 13 & (2.8) \\
\hline 3rd Trimester & 452 & $(96.6)$ \\
\hline \multicolumn{3}{|l|}{ Services received $(n=470)$} \\
\hline Ultrasonography & 466 & $(99.1)$ \\
\hline Bloodpressure & 445 & (94.7) \\
\hline Blood sugar & 108 & $(23)$ \\
\hline General urine examination & 317 & $(67.4)$ \\
\hline Iron and folic acid & 436 & $(92.8)$ \\
\hline Tetanus vaccine & 313 & $(66.8)$ \\
\hline
\end{tabular}


A statistically significantly higher proportion of employed women utilized antenatal care adequately compared with housewives (84\% vs. $63.4 \%, P=0.036$ ). No statistically significant association could be detected between the mothers' age and education with the utilization of adequate antenatal care. These findings are shown in Table 4.

\section{Discussion}

Conflicts and their aftermaths can have terrible consequences for reproductive health. The majority of political emergencies occur in the world's poorest nations, where the population's pre-conflict health is often already suboptimal. ${ }^{9}$ These crises can lead to a sharp decline in access to health services. As health systems collapse and people flee in search of safety, access to health facilities that can offer safe delivery, provide emergency cesarean sections, or treat other complications of pregnancy and childbirth becomes limited or eliminated entirely. ${ }^{10}$ Conducting such a study in Syrian refugee camps in Erbil, where no previous similar studies have been conducted, provides information to the health authorities and policymakers regarding the status and assessment of antenatal care services. In the present study, almost all the pregnant women reported at least one antenatal visit $(99.6 \%)$, which is more than that reported in Syria (88\%) before the conflict. ${ }^{11}$ Such coverage was also more than that reported in previous studies in Erbil (82.4$86.1 \%)^{12,13}$ and the other governorates in Iraqi Kurdistan $(80-85.1 \%) .{ }^{14-16}$ In this study, $64.7 \%$ of newly delivered women reported receiving adequate antenatal care, which agrees with that reported in Syria before the conflict $(64 \%) .{ }^{11}$ The WHO reported that the percentage of women who were receiving at least four antenatal visits in low-income countries ranges between $56 \%$ for rural women to $72 \%$ for urban women with an estimated $38 \%$ in the least developed countries and $50 \%$ worldwide. ${ }^{4}$ In the current study, $31.2 \%$ of newly delivered women sought antenatal care from public health centers only during the last pregnancy, which is higher than

Table 4: Association between utilization of antenatal care and mothers' factors.

\begin{tabular}{lcccc}
\hline Variable & $\begin{array}{c}\text { Adequate } \\
\text { antenatal care } \\
\text { No. (\%) }\end{array}$ & $\begin{array}{c}\text { No or inadequate } \\
\text { antenatal care } \\
\text { No. (\%) }\end{array}$ & $\begin{array}{c}\text { Total } \\
\text { No. (\%) }\end{array}$ & P value \\
\hline Mother's age (years) & & & & \\
$<20$ & $30(73.2)$ & $11(26.8)$ & $41(100)$ & \\
$20-24$ & $86(60.6)$ & $56(39.4)$ & $142(100)$ & \\
$25-29$ & $106(67.9)$ & $50(32.1)$ & $156(100)$ & 0.437 \\
$30-34$ & $55(60.4)$ & $36(39.6)$ & $91(100)$ & \\
$\geq 35$ & $26(65.0)$ & $14(35.0)$ & $40(100)$ & \\
Mother's education & & & & \\
Illiterate & $70(65.4)$ & $37(34.6)$ & $107(100)$ & \\
Primary & $127(59.9)$ & $85(40.1)$ & $212(100)$ & \\
Secondary & $64(66.3)$ & $34(34.7)$ & $98(100)$ & 0.070 \\
Post-secondary education & $42(71.7)$ & $11(20.8)$ & $53(100)$ & \\
Mother's occupation & & & & \\
Housewives & $282(63.4)$ & $163(36.6)$ & $445(100)$ & 0.036 \\
Employed & $21(84)$ & $4(16)$ & $25(100)$ & \\
\hline
\end{tabular}


the rates reported in previous studies from Duhok governorate $(13.4 \%)^{14}$ and Erbil city $(11.4 \%)^{13}$ Only $4.7 \%$ reported seeking antenatal care from the private clinic only; which is lower than the rates reported in previous studies from different governorates of Iraq including Diyala governorate $(35 \%),{ }^{15}$ Duhok governorate $(86.6 \%)^{14}$ and Erbil city (26.4\%). ${ }^{13}$ Nearly two-thirds of the participants (64.1\%) visited both the public and private facilities to seek antenatal care. Lack or poor quality of care in the public sector make people prefer seeking care in the private sector. However, the private sector is not always affordable for people, especially the refugees who suffer from economic hardship. In the current study, $93.2 \%$ of mothers had their first visit to antenatal care in the first trimester in their last pregnancy. This rate is higher than that reported in Diyala governorate $(46.8 \%)^{15}$ and Erbil city (55.6-62\%). ${ }^{12,13}$ Studies from other settings have shown a large variation in the proportion of women starting antenatal care in the first trimester ranging from $35 \%$ in Ethiopia ${ }^{17}$ to $73 \%$ in Benghazi. ${ }^{18}$ The relatively high rate of antenatal care coverage rate reported in this study can be traced back to the fact that every single camp has its health care center which is located in the refugee camps, so they did not face transportation problems. Moreover, all the services were free, and every pregnant woman has received incentives from the nongovernmental organization in the form of food, clothes, blankets, and artificial milk for the newly delivered babies. The present study revealed that there was no significant association between the age of the mother and adequate antenatal care utilization; which agrees with that reported in Erbil city, ${ }^{12}$ Benghazi, ${ }^{18}$ and Karachi. ${ }^{19}$ However, it disagrees with a study from Nepal, which revealed a significant association between maternal age and antenatal care attendance. $^{20}$ In the current study, there was not any significant association between the mother education and the utilization of adequate antenatal care; a finding that agrees with another study from Ecuador. ${ }^{21}$ However, studies from Erbil city, ${ }^{12,13}$ Turkey, ${ }^{22}$ and Nepal ${ }^{20}$ have found a significant association between the mother education and utilization of antenatal care. The relatively small sample size of the current study might be responsible for failure to detect a significant relationship between the mother education and utilization of antenatal care even if it exists. A significant association was found between mother's employment status and utilization of adequate antenatal care in this study, which agrees with other studies from Erbil city, Turkey and Nepal. ${ }^{12,13,20,22}$

\section{Conclusion}

A high proportion of women in the Syrian refugee camps in Erbil received antenatal care services during the last pregnancy with a relatively important proportion of women receiving adequate care and having early initiation of antenatal care visits. Women's employment was significantly associated with better use of adequate antenatal care. Further studies are needed to examine the quality of the antenatal care services in the refugee camps and women's satisfaction with these services.

\section{Competing interests}

The authors declare that they have no competing interests.

\section{References}

1. Banta D. What is the efficacy/effectiveness of antenatal care and the financial and organizational implications. Copenhagen: WHO Regional Office for Europe; 2003.

2. Park K. Parks textbook of preventive and social medicine. $23^{\text {rd }}$ ed. Jabalpur, India: Banarsidas Bhanot; 2015.

3. WHO. WHO recommendations on antenatal care for a positive pregnancy experience. Geneva: WHO; 2016.

4. WHO. Global health observatory data: Maternal and reproductive health 2017. (Accessed July 17, 2017, at http://www.who.int/gho/maternal_health/ en/). 
5. WHO. Antenatal care: Situation and trends 2017. (Accessed July 12, 2017, at http://www.who.int/ gho/mdg/maternal_health/antenatal_care_text/ en/).

6. Benage $M$, Greenough PG, Vinck $P$, Omeira N, Pham P. An assessment of antenatal care among Syrian refugees in Lebanon. Confl Health 2015; 9:8.

7. Villar J, Bergsjo P. WHO Antenatal Care Randomized Trial: Manual for the implementation of the new model. Geneva: WHO; 2003.

8. Villar J, Ba'aqeel H, Piaggio G, Lumbiganon $P$, Miguel Belizan J, Farnot U, et al. WHO antenatal care randomized trial for the evaluation of a new model of routine antenatal care. Lancet 2001; 357(9268):1551-64.

9. Cohen S. The reproductive health needs of refugees and displaced people: an opening for renewed US leadership. Guttmacher Policy Review 2009; 12(3):15-9.

10. McGinn T. Reproductive health of war-affected populations: what do we know? Int Fam Plan Perspect 2000; 26(4):174-80.

11. UNICEF. At a glance: Syrian Arab Republic. UNICEF; 2013.

12. Dhahir AA, Zangana JM. Determinants of utilization of antenatal care services in Erbil city. Zanco J Med Sci 2015; 19(2):984-90.

13. Hussein NA. Antenatal care: effectiveness and implication on pregnancy outcome in Erbil city. MSc thesis. Erbil, Iraq: Hawler Medical University; 2011.

14. UNICEF, Kurdistan Regional Ministry of Health. Low birth weight study in Duhok Governorate. Iraqi Kurdistan. Iraq: UNICEF; 2007.

15. Abdul Latif BI. The pattern of morbidity and mortality of neonate admitted to neonatal intensive care unit in Saddam Maternity and Pediatric Hospital in Diyala governorate 19992000. Baghdad, Iraq: University of Baghdad; 2001.

16. UNICEF, COSIT, KRSO, MOH. Multiple Indicator Cluster Survey 2006, Volume 1: Final Report. Iraq: UNICEF; 2007.

17. Gudayu TW, Woldeyohannes SM, Abdo AA. Timing and factors associated with first antenatal care booking among pregnant mothers in Gondar Town; North West Ethiopia. BMC Pregnancy Childbirth 2014; 14:287.

18. Ziyo FY, Matly FA, Mehemd GM, Dofany EM. Relation between prenatal care and pregnancy outcome at Benghazi. SJPH 2009; 4(4):403-10.

19. Nisar N, White F. Factors affecting utilization of antenatal care among reproductive age group women (15-49 years) in an urban squatter settlement of Karachi. J Pak Med Assoc 2003; 53(2):47-53.

20. Tuladhar H, Dhakal N. Impact of antenatal care on maternal and peri-natal outcome: A study at Nepal Medical College Teaching Hospital. NJOG 2012; 6(2):37-43.
21. Paredes I, Hidalgo L, Chedraui P, Palma J, Eugenio J. Factors associated with inadequate prenatal care in Ecuadorian women. Int $\mathrm{J}$ Gynaecol Obstet 2005; 88(2):168-72.

22. Ciceklioglu M, Soyer MT, Ocek ZA. Factors associated with the utilization and content of prenatal care in a western urban district of Turkey. Int J Qual Health Care 2005; 17(6):5339. 